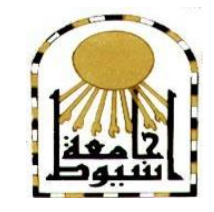

\title{
كلية التزبية
}

كلية معتمدة من الهيئة القومية لضمان جودة التعليم

مجلة دراسات في مجال الارشاد النفسي والتربوي- كلية التربية- جامعة أسيوط

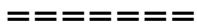

التدفق النفسى و علاقته باضطر اب قلق الكلام لاى الأطفال المعاقين عقليًا القابلين للتعلم

\section{9)(9)}

الباحث/ بيتر مجدى حبيب أبادير

مدرس بمدرسة الفرنسيسكان الخاصة بأسيوط

ماجستير فى التربية الخاصة (تخصص تخاطب)

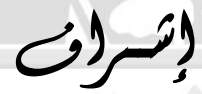

د/ إيمان صلاح الدين حسين

الثربف

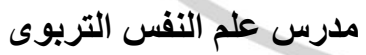

كلية التربية - جامعة أسيوط
د/مصطفـى عبد المحسـن

الحدبيى عبي

أستاذ الصحة النفسية المساعد

كلية التربية - جامعة أسيوط

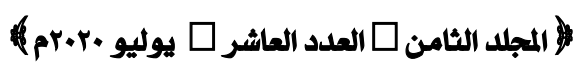

https://dapt.journals.ekb.eg

Your username is: ali_salah790@yahoo.com

Your password is: ztu6y8qupw 
د/مصطفى عبد المحسن الحديبى د/ إيمان صلاح الدين حسين الثريف أ/بيتر مجدى حبيب أبادير

\section{أولاً: مقدمة الدراسة}

تمثل مرحلة التعليم العام مرحلة مهمة في حياة الأفراد، وبخاصة التعليم الابتدائي وذلك

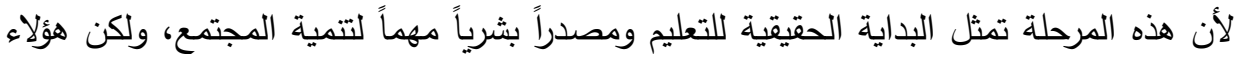

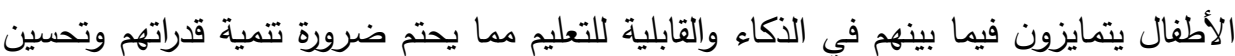
أساليب تفكيرهم وتعلمهم وتوجه دوافعهم نحو التعلم.

ويسعى علم النفس والصحة النفسية بشكل أساسي إلى الوصول بالنفس البشرية إلى قمة

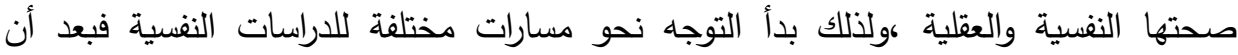

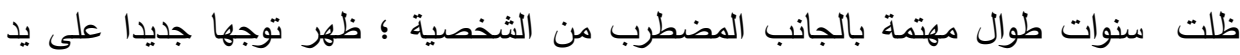

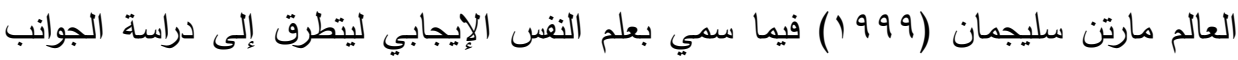

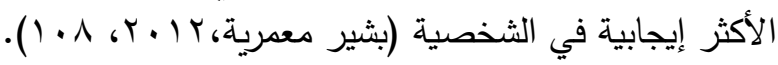

ولكن بعض الأطفال يعاني من ذوي الإعاقة العقلية من بعض المشكلات اللغوية،

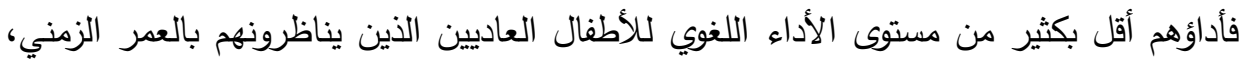

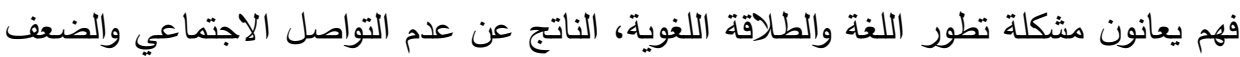

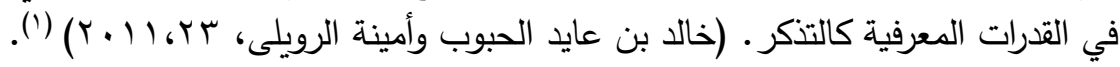
والأطفال ذوي الإعاقة العقلية يواجهون مفرداتهم بسيطة لا تتتاسب مع عمرهم الزمني

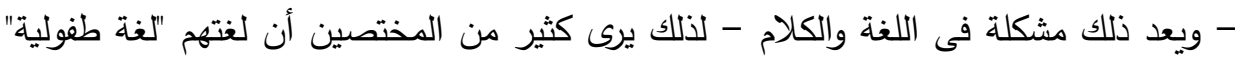

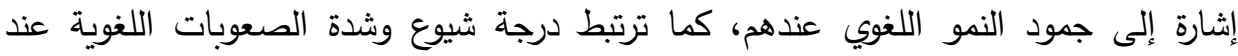

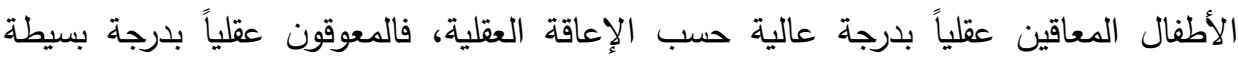

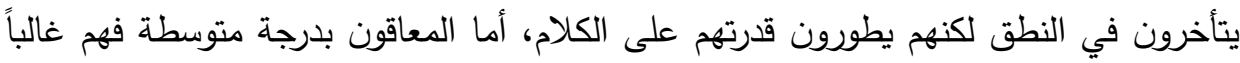

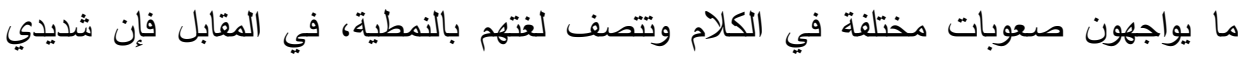

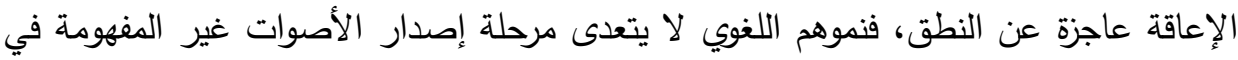

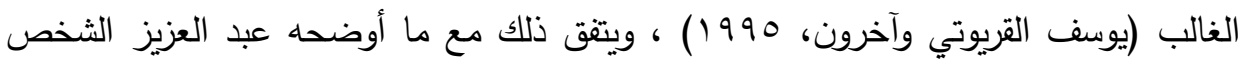

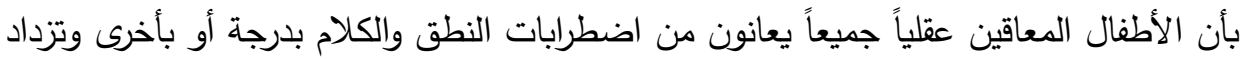

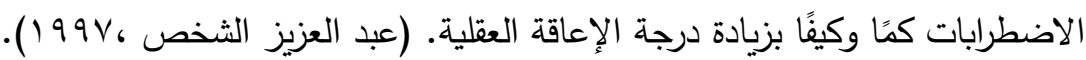
ومن الأسباب التي تجعل الطفل المعاق عقلياً يتجنب التواصل مع الآخرين تفكيره بأنه

(')(التوثيق وفقا لاليل جمعية علم النفس الأمريكية APA حيث يثير الرقم الأول إلي سنة النشر للمرجع، ويثير الرقم الثاني إلي رقم الصفحة أو الصفحات بذات المرجع. 
مجلة دراسات فى مجال الإرشاد النفسي و التربوي ـ كلية التربية ـ جامعة أسيوط

سيتم الحكم عليه من خلال الحديث الذي سيلقيه أمام الاخرين، وأن الكلمة التي يلقيها هي أساس

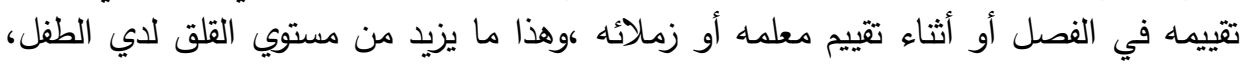

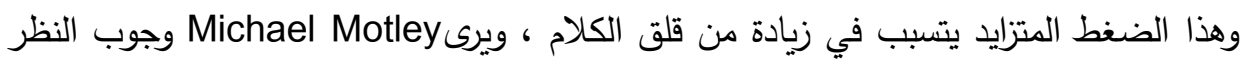

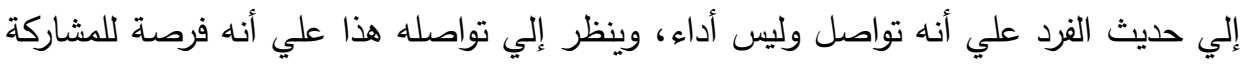

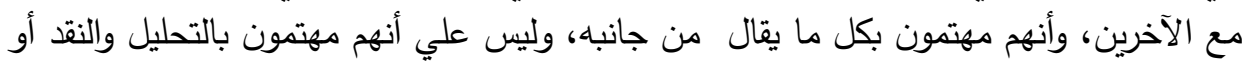

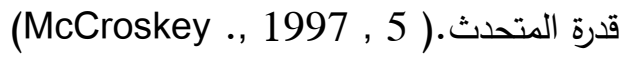

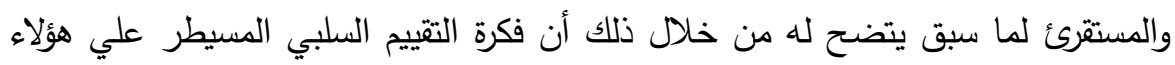

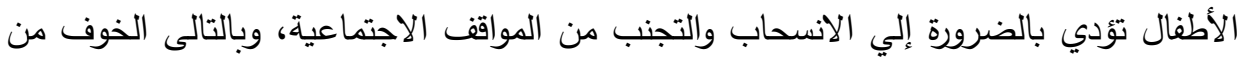

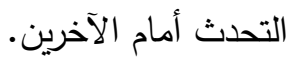

حيث أكدت بعض الدراسات وجود ارتباط بين الانطواء وقلق الكلام، ومن سمات الطفل

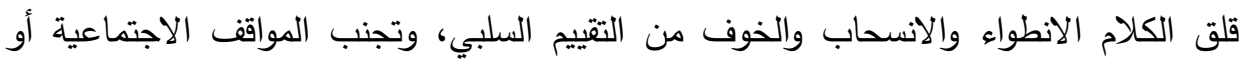

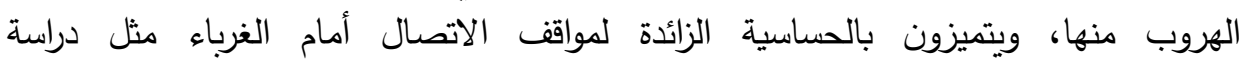

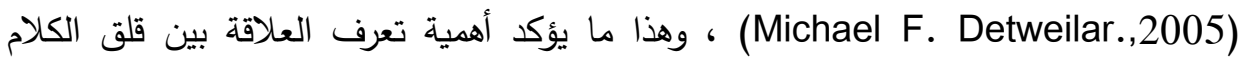

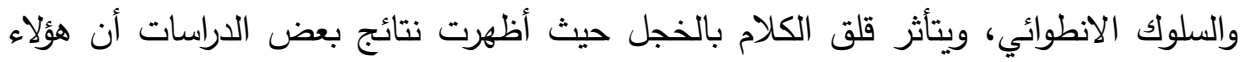

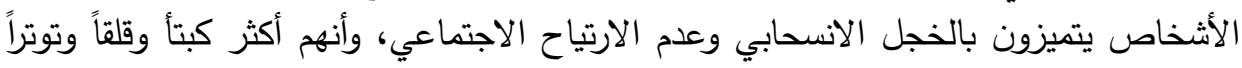

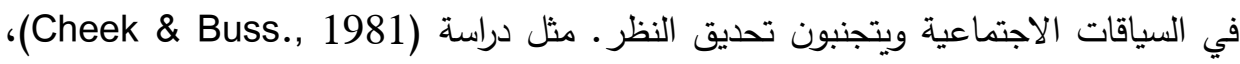

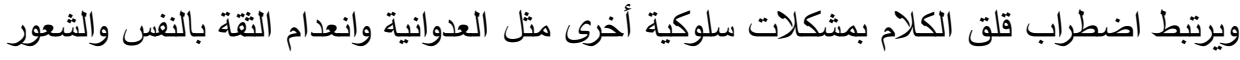
بالنقص والغضب وتظهر العدوانية على شكل مماطلات ونوبات غضب ألثات أثناء الحديث بالكلام

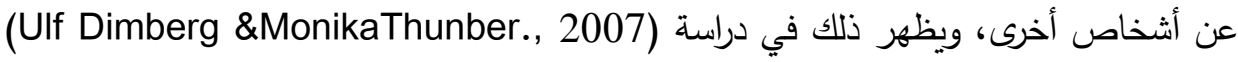

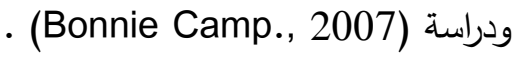

ويعد قلق الكلام أحد اضطرابات الطلاقة النفسية للكلام التي تؤدي بالأطفال المعاقين

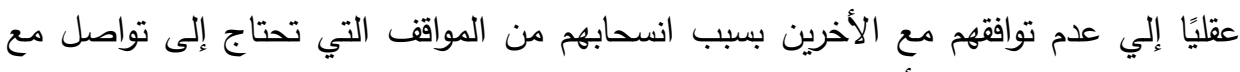

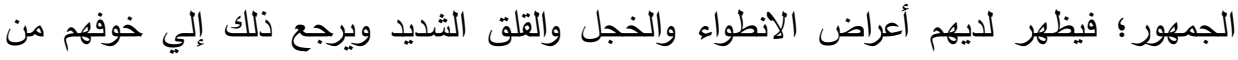

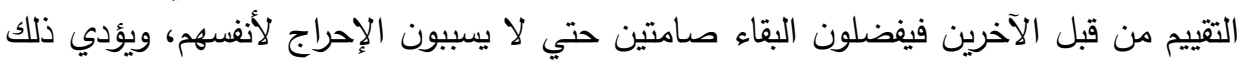

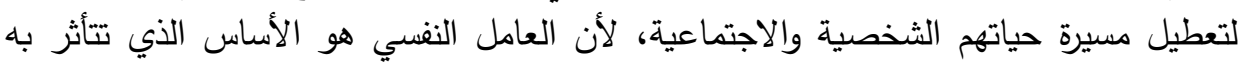

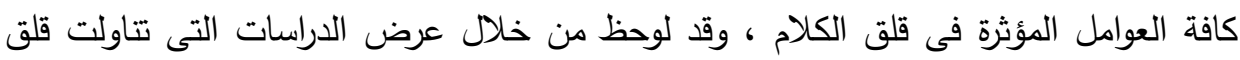

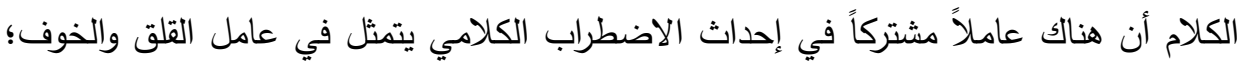
فالقلق الذي يصاحب عملية الكلام هو السبب في نشأة الاضطراب الكلامي لإي الأطفال.

ويُعد تبنى معنى إيجابيًا فى الحياة أحد المتغيرات التى يسعى الانسان لتحقيقها 
د/مصطفى عبد المحسن الحديبى د/ إيمان صلاح الدين حسين الشريف أ/بيتر مجدى حبيب أبادير

ولإضفاء قيمة لوجوده من خلالها، إلا أن مطالب الآخرين منه والظروف التى يمر بها الأطفال المعاقون عقليًا القابلون للتعلم أدت إلى ظهور مشكلات نفسية لغوية لديهم كمشكلة قلق الكلام

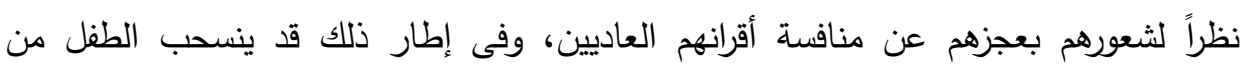

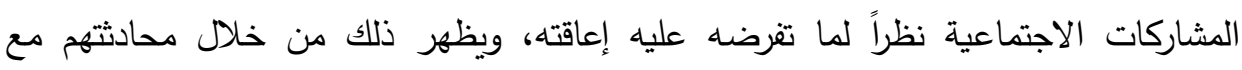
الآخرين وهو ما يُعرَف بقلق الكلام.

ولقد تتاولت العديد من الدراسات العلاج النفسى الإيجابى فى التخفيف من المشكلات النفسية والاجتماعية لذوى الاحتياجات الخاصة والعاديين، حيث هدفت دراسة Asl et al (2014) السعادة لاى النساء المصابات بالعقم ، وتتاولت دراسة (2012) Meyer et al فاعلية العلاج النفسى الإيجابى فى زيادة السعادة، والمشاركة الإيجابية فى الحياة، والرفاهية لاى عينة من

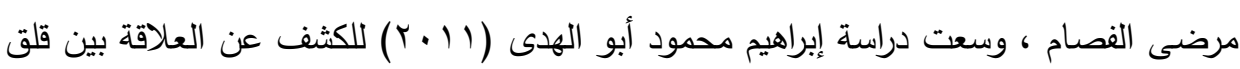
المستقبل ومعنى الحياة ووجهة الضبط لدى عينة من طلاب الجامعة المعاقين بصرياً

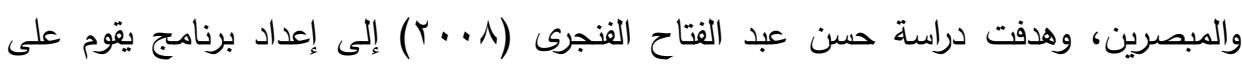
إستراتيجيات علم النفس الإيجابى، وقياس ددى فعالية هذا البرنامج فى التخفيف من قلق المستقبل لاى عينة من طلاب الجامعة.

والتدفق حالة ينهك فيها المرء للغاية في نشاط بحيث يكون كل شيء آخر غير مهم ،

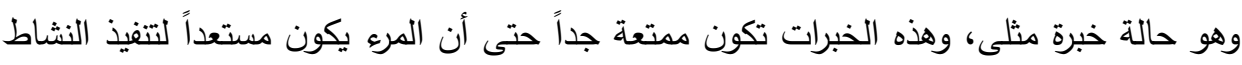
حتى إذا كان هذا النشاط يعرضه للخطر ، أو يحمل في طياته نفقات اقتصادية كبيرة ،وحالة التدفق هذه تتميز بالانهماك والتركيز وكون الثخص موجوداً بالكامل في الحاضر ، وتصبح الساعات دقائق والعكس صحيح. وبذلك يكون النشاط المعطى الذي يستحث التدفق يكون محفزًا ومدفوعًا للغاية بدافعية داخلية بحيث يصبح النشاط هدفاً في حد ذاته.

ويتقق ذلك مع ما أوضحه (جولمان) بأن التدفق النفسى هو استغراق الإنسان فى أداء مهمة ما حتى يبلغ ذروتها، ويستمر هذا التدفق بعد ذلك بأقل مجهود كالثلال المتدفق، فإذا 
مجلة دراسات فى مجال الإرشاد النفسي و التربوي ـ كلية التربية ـ جامعة أسيوط

استطاع الفرد أن يصل إلى حالة التدفق فإن ذلك يمثل أقصى درجة للأداء الإيجابى الملئ بالطاقة التى تقى الفرد من الإصابة بالملل والاكتئاب والتوتر والتلق. (Seligman.,2002) وتتاولت بعض الدراسات علاقة التدفق النفسى بالمشكلات النفسية مثل دراسة صديق ومحد السيد (9 . . r) التى سعت الى معرفة العلاقة بين التدفق النفسى وبعض العوامل النفسية كالاعتماد على النفس والمثابرة، والرضا عن الذات والقلق والاكتئاب، وسعت دراسة سيد البهاص

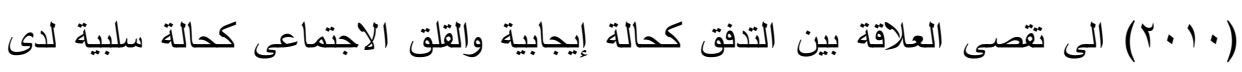
مستخدمى الإنترنت.

والتدفق يجعل الطفل منعزلًا عما حوله لينفرد بعمله الذى يقوم به متجرداً من كل ما هو

محيط به، ويعيش فى حالة من التوحد تكون فيه المعاناة مصدر سعادة ودافعًا للاستمرار لا مصدر إحباط، وبالتالى يحدث تواصل داخلى للأطفال المعاقين عقلياً القابلين للتعلم وهذا ما

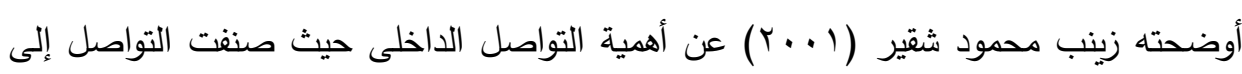
التواصل الداخلى، والتواصل بين الفرد والآخرين، والتواصل بين الجماعات الاجتماعية، وأن التواصل الداخلى هو التواصل بين الفرد وذاته وعلاقاته بالمحيطين به وتقييمه الثخصى لقدراته وكيفية توظيفه لهذه القدرات والإمكانات، ونجاح الفرد فى ذلك يحدد بدرجة كبيرة بنجاحه فى التقاعل مع الآخرين، ويمثل ذلك الأساس الذى يعتمد عليه الفرد فى تواصله مع نفسه ومع

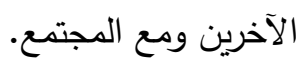

ويسعى الباحث فى هذة الدراسة إلى التعرف على العلاقة بين التدفق النفسى وقلق الكلام

لدى الاطفال المعاقين عقليًا القابلين للتعلم المدمجين بمدارس التعليم العام. ثانياً: مشكلة الدراسة:

نبع إحساس الباحث بالمشكلة من رؤيته للأطفال المعاقين عقلياً القابلين للتعلم الدمجين 
د/مصطفى عبد المحسن الحديبى د/ إيمان صلاح الدين حسين الشريف أ/بيتر مجدى حبيب أبادير

فى أحدى مدارس التعليم العام بأسيوط من وجود أعراض لقلق الكلام لديهم مثل تجنب المشاركة فى الحوار وضيق التنف والعرق الثديد وارتعاش اليد والكلام غير المفهوم مثل تكرار كلمة (بس) أو (يعنى) أو (امم) وذلك بشكل ملاحظ وبالتالى انخفاض معدل الطلاقة اللغوية. ودعم إحساس الباحث بالمشكلة ما أسفرت عنه نتائج الدراسات السابقة حول طبيعة ومظاهر قلق الكلام، حيث أوضح حمدى الفرماوى (T . . r) أن مظاهر قلق الكلام فى ثلاث مظاهر رئيسة وهى المظاهر البدنية مثل برودة الأيدى والأقدام، وارتعاش بالأيدى والجسم والارتجاف والتصبب عرقاً، وجفاف الحلق ودقات قلب سريعة لا يمكن للجمهور سماعها، وخفقان القلب وصوت مهزوز، ومعدة مضطربة وصعوبة فى التنف،ومظاهر نفسية مثل الثعور بالتوتر العصبى وتجنب المشاركة فى الحوارات، وتجنب الاتصال بالغير، وعدم الثقة بالنفس وخوف شديد وأفكار سلبية، ومظاهر معرفية مثل اضطراب الأفكار وتداخلها وصعوبة تتظيم الأفكار وترتيبها أثثاء الحديث ونسيان الحقائق وصعوبة استدعاء الكلمات الملائمة للموقف وانخفاض معدل الطلاقة اللغوية.

وتعد مشكلة اللغة لدى الاطفال المعاقين عقلياً القابلين للتعلم من المشكلات المهمة التى تحتاج البحث والدراسة؛ نظراً لازدياد نسبة ظهور هذة الحالات ولصعوبة اكتشافها من جانب الأسرة والمتخصصين فى مراحل مبكرة من حياة الطفل، ولتداخلها مع العديد من الأعراض المرضية، والتى تضع الآباء فى حيرة من أمرهم وتتفاقم المشكلة كلما زاد عمر الطفل وكبرَ سنه فيظهر ضعف قدرته على التعبير عن احتياجاته ومشاعره وعدم القدرة على التفاعل مع من هم فى سنه أو أكبر سناً منه، ويظهر ميله لكثرة التعامل مع هم فى سن أصغر منة لسهولة تفاعلهم اللغوى.

وتشير الإحصاءات إلى أن فئة المعاقين بشكل عام والمعاقين عقليًا بشكل خاص تمثل شريحة كبيرة سواء أكانت على المستوى العالمي أم المستوى المحلي، حيث يثير تقرير الجهاز

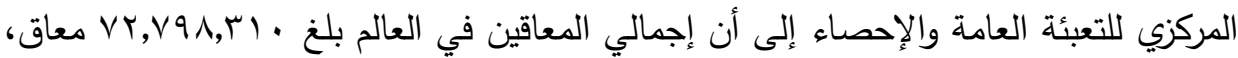


مجلة در اسات فى مجال الإرشاد النفسي و التربوي ـ كلية التربية ـ جامعة أسيوط

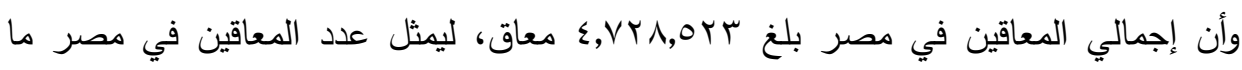

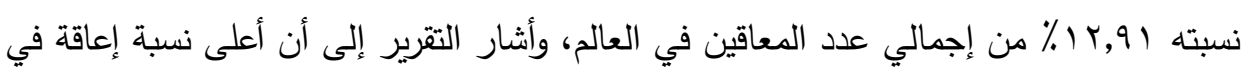

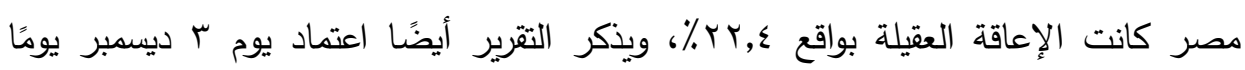

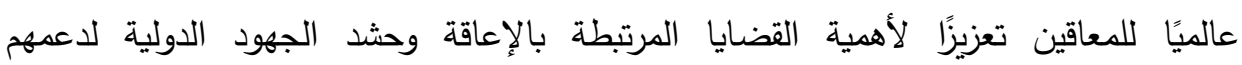

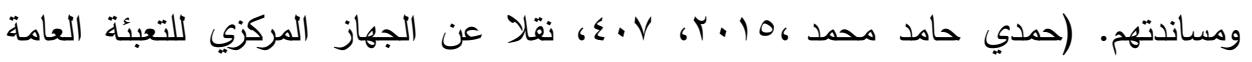

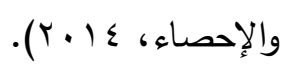

ويظهر الخلل اللغوى متمثلًا فى الثكل والمضمون والتراكيب اللغوية واضطراب فى النطق وضعف الطلاقة اللغوية، ويتضح ذلك جليًا لاى الأطفال ذوى الإعاقة العقلية القابلين للتعلم، وذلك لضعف قدراتهم العقلية والتىى من ثم ضعف قدراتهم النفس اللغوية، وبالتالى يكون لها عظيم الآثر فى ضعف قدراتهم للتعبير عن أنفسه ومشاعرهم واحتياجاتهم ومتطلباتهم، وقدرتهم على التفاعل مع الآخرين ومن ثم اندماجهم مع أسرهم ومجتمعهم. وتعد اضطرابات الطلاقة والتواصل من المشكلات الثائعة عند الأطفال المعاقين عقلياً القابلين للتعلم وينتج عنها عدم القدرة على التفاعل مع الآخرين من خلال الحوار، بالإضافة

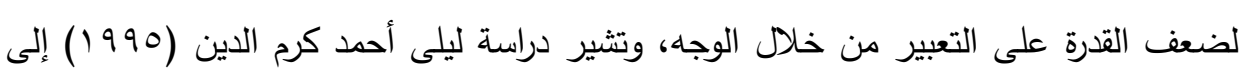
أن قدرة الطفل المعاق عقليًا على استخدام الوجه للتعبير عن مشاعره تعتبر ضئيلة، وأن ما يعبر

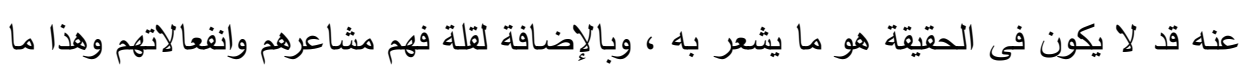

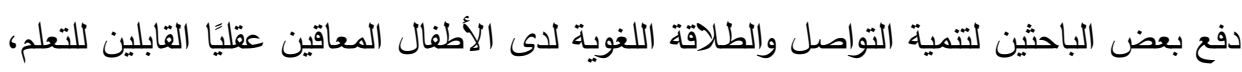
وانعكاس ذلك على الجوانب العقلية المعرفية.

وبالتالى تتحدد مشكلة الدراسة فى السؤال الرئيس التالى: ما العلاقة بين التدفق النفسى وقلق الكلام للأطفال المعاقين عقلياً القابلين للتعلم المدمجين؟ ثالثاً: أهداف الدراسة: - مان تهرف الدراسة الحالية إلى: 
د/مصطفى عبد المحسن الحديبى د/ إيمان صلاح الدين حسين الثريف ألبيتر مجدى حبيب أبادير

التعرف على العلاقة بين التدفق النفسى وقلق الكلام للأطفال المعاقين عقلياً القابلين للتعلم المدمجين. رابعًا: أهمية الدراسة تظهر أهمية الدراسة الحالية فيما يلى: 1- إلقاء الضوء على مشكلة قلق الكلام فضلًا عن تجسيد خطورة ذلك على النمو النغسى للأطفال المعاقين عقلياً القابلين للتعلم المدمجين بمدارس التعليم العام، وتأثير ذلك الاضطراب على جميع النواحى النفسية والاجتماعية. ץ- إلقاء مزيد من الضوء على العلاج النفسى الإيجابى ؛كونه اتجاهاً حديثًا فى العلاج النفسى. ب- مساعدة وتوجيه نظر المختصين والقائمين على رعاية الأطفال المعاقين عقلياً وخاصة بمدارس الدمج الى الطرق والحلول المناسبة التى يمكن الاستفادة منها لخفض قلق الكلام عن طريق العلاج النفسى الإيجابى وتتمية التدفق لايهم. خامساً: مصطلحات الدراسة:

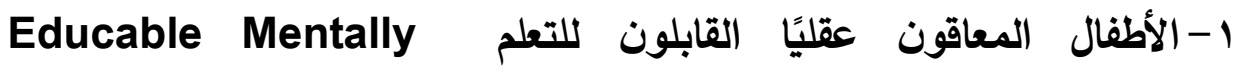
: Retarded Children

يستخدم هذا المصطلح لوصف المستويات العليا من الإعاقة العقلية، والتى تضم أطفالاً

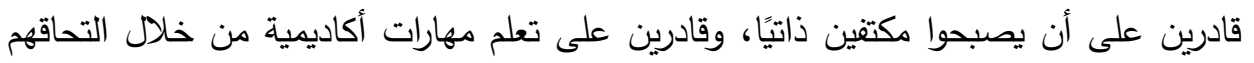

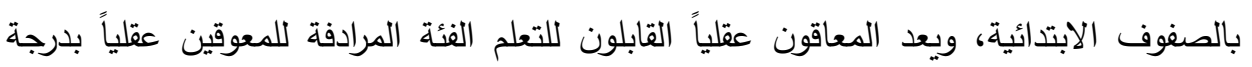
بسيطة فى النظام التصنيفى الخاص بالجمعية الأمريكية للضعف العقلى، كما يعتبر مدى نسبة

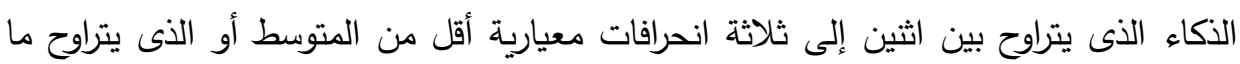

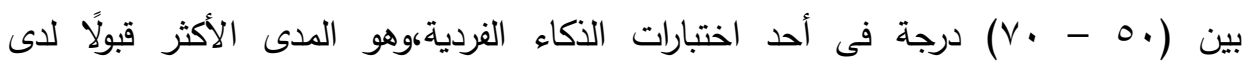

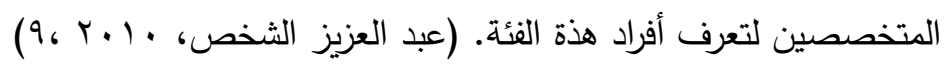

r - التدفق النفسى FlowPsychological:

حالة نفسية تصاحب الأنشطة الجذابة للغاية فالوقت يمر بسرعة، ويكون الانتباه مركزاً 
مجلة دراسات فى مجال الإرشاد النفسي و التربوي ـ كلية التربية ـ جامعة أسيوط

تماماً على النشاط، ويفقد الشعور بالذات (1996,. Moneta \& Csikszentmihaly). يحدث التدفق لدى الكثير من الاشخاص حتى أولئك الذين يمارسون أنثطة دون مقابل ، إذ يكون النشاط الممارس هدفاً فى حد ذاته ويشعر الفرد بالمتعة والسرور ، ويعتقد Csikszentmihaly أن الفرد يصل إلى حالة التدفق النفسى عندما يؤدى الانثطة المثالية والتى تتحرك خارج اطار القيود والتحديات مع سيطرة الفرد على مهاراته التى تحرره من البلادة النفسية والسلوكية ، ويتكون التدفق النفسى من كافة القدرات والمواهب التى يستعمها الفرد لمواجهة التحديات التى تواجة الحياة ، وان الانشغال بالإنجازات يعد المكافاة العادية فى الحياة المنتجة ، والانشغال بالحياة المنتجة التى تتدفق انجازاتها لا يتولد عنها السرور والمتعة والثعور باللذة فقط ولكنها بالضرورة يتولد عنها الثعور بالرضا والسعادة وتحقيق الذات وتحقيق السمو وضبط الذات ، كما يرى أن تدفق الفرد قادراً على مواجهة التحديات عملياً.

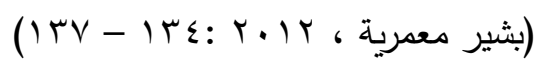

التعريف الاجرائى: هى الدرجة الكلية التى يحصل عليها الطفل عند إجابته على فقرات

مقياس التدفق النغسى المعد فى الدراسة الحالية.

ب- قلق الكلام Speech Anxiety:

يعد قلق الكلام أحد اضطرابات القلق الاجتماعي وفيه يشعر الفرد بالذوف من التحدث أمام الجمهور؛ فقد يثعر بالتوتر الاجتماعي الذي يظهر عند حديثه أثناء كلامه مع الآخرين، ويؤدي ذلك إلى مظاهر الانسحاب الاجتماعي ( 3 , 2009,. Joseph Goldfard). يمكن أن يعرف قلق الكلام بأنه أحد اضطرابات الطلاقة النفسية للكلام الذي يعاني منه الفرد للخوف من التقييم السلبي، وهو حالة من الاكتئاب يتميز فيه الفرد بالحساسية المفرطة 
د/مصطفى عبد المحسن الحديبى د/ إيمان صلاح الدين حسين الثريف أ/بيتر مجدى حبيب أبادير

والخوف الاجتماعي، مما يؤدي إلي عدم قدرة الفرد علي التواصل مع الآخرين، وفي كل أحواله المضطربة يتميز بالمشقة والتوجس والخشية نتيجة شعوره بالتهديد سواء كان حقيقياً أو متوهماً وقد يصاحب كل ذلك كثير من الاضطرابات السلوكية والاجتماعية لذلك لا يمكن تفسيره الا من خلال منظور متكامل.

التعريف الاجرائى: الدرجة التي يحصل عليها المفحوص علي مقياس قلق الكلام للأطفال

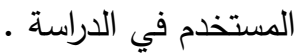

سادسًا: فرض الدراسة:

ينص على:" توجد علاقة ارتباطية دالة احصائية بين التدفق النفسى وقلق الكلام للأطفال

المعاقين عقلياً القابلين للتعلم المدمجين "

سابعًا: منهج الدراسةة:

يستخدم الباحث المنهج شبة التجريبى وذلك بغرض دراسة العلاقة بين التدفق النفسى وقلق الكلام لدى الاطفال المعاقين عقليًا القابلين للتعلم المدمجين بمدارس التعليم العام، من خلال تحديد مجموعه تجريبية لتطبيق مقياس قلق الكلام ومقياس التدفق النفسى عليهم لتحديد العلاقة بينهما

ثامنًا: المشاركون بالدراسة: 1- المشاركون بالدراسة الاستطلاعية:

اختار الباحث(• (ب) طفلًا من الأطفال المعاقين عقليًا القابلين للتعلم المدمجين من مدارس التعليم العام بأسيوط للتحقق من كفاءة أدوات الدراسة.

r- المشاركون بالدراسة الأساسية : 
مجلة در اسات فى مجال الإرشاد النفسي و التربوي ـ كلية التربية ـ جامعة أسيوط

اختار الباحث اب من الأطفال المعاقين عقليًا القابلين للتعلم المدمجين من مدارس التعليم

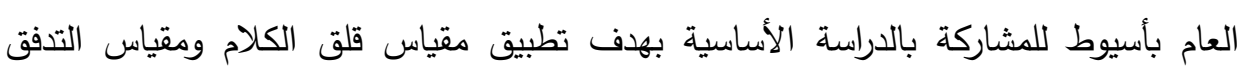
النفسى عليهم. تاسعًا: أدوات الدراسة: ا-مقياس التدفق النفسى للاطفال المعاقين عقلياً القابلين للتعلم ذوى اضطراب قلق الكلام: (أ) خطوات إعداد المقياس:

قام الباحث بإعداد مقياس التدفق النفسى للأطفال المعاقين عقلياً القابلين للتعلم ذوى

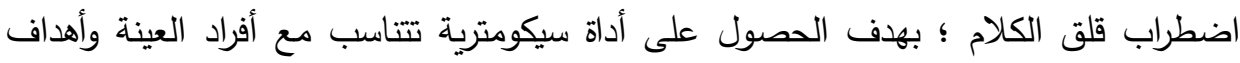

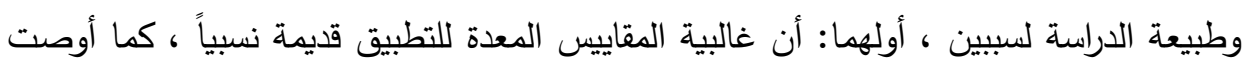

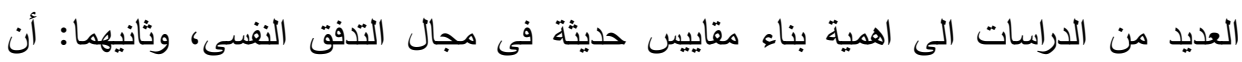

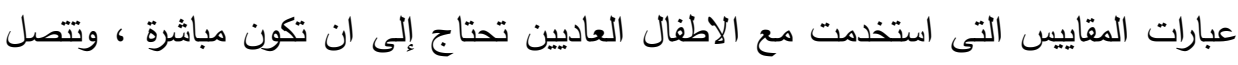
بمستوى التدفق النفسى للاطفال المعاقين عقلياً القابلين للتعلم ذوى اضطراب التعاب قلق الكلام. ولذلك فمن دواعى بناء المقياس أن يعتمد فى بنائة على عوامل ترتبط بمستوى تقبل

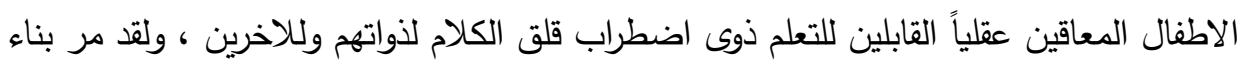

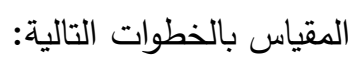
- الاطلاع على نظرية التدفق النفسى لـ (2008) Csikszentmihaly واتخاذها مرجعاً نظرياً ستعتمد أبعادها فى قياس ظاهرة البحث وتفسيرها.

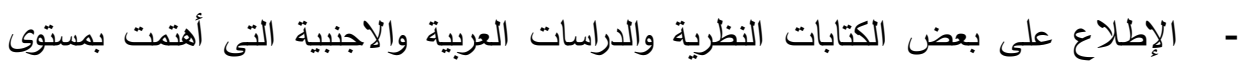
التدفق النفسى ، وعلاقتها ببعض المتغيرات النفسية الاخرى.

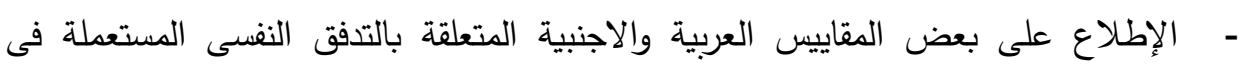

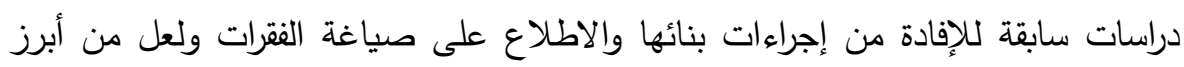

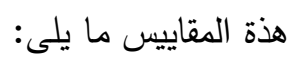
1- مقياس حالة التدفق إعداد عفراء إبراهيم خليل (T ( • ץ). 
د/مصطفى عبد المحسـن الحييى د/ إيمان صلاح الدين حسين الثريف أ/بيتر مجدى حبيب أبادير

$$
\text { r- مقياس التدفق النفسى إعداد عبد العزيز حيدر وآنس أسود (7 ( ب). }
$$

Jackson \& Marsh إعداد The Flow State Scale re مقياس التدفق النفسى - فى ضوء المتغيرات النفسية المرتبطة بالتدفق النفسى ، وطبيعة وخصائص أفراد العينة ، تم صياغة فقرات المقياس فى صورتها الأولية بما يناسب مع أسس العلاج الانتقائى والمتغيرات المرتبطة بالتدفق النفسى ؛ لتعبر عن التدفق النفسى للاطفال المعاقين عقلياً القابلين للتعلم ذوى اضطراب قلق الكلام حيث تمثل عدد عبارات مقياس التدفق النفسى للاطفال المعاقين عقلياً القابلين للتعلم ذوى اضطراب قلق الكلام (^ا) عبارة تقيس كل ابعاد التدفق النفسى التسع وقد روعى عند صياغة الفقرات ان تكون بصيغة المتكلم وان تقيس الفقرة فكرة واحدة فقط وعدم استعمال صيغة نفى النفى كى لا تربك المفحوص ولها بديلين هما: (نعم - لا) على أن تكون درجات كل فقرة على الترتيب (1 - · ) للعبارات

$$
\text { الايجابية ، و (· - ( ) للعبارات السلبية. }
$$

(ب) الخصائص السيكومترية لمقياس التدفق النفسى:

أولاً: الصدق:

اعتمد الباحث فى حساب الصدق على ما يلى:

أ-الصدق المنطقى ( صدق المحكمين ):

تم عرض المقياس على مجموعة من الدكمين وذلك بهدف: التأكد من مناسبة مفرداته، تحديد غموض بعض المفردات لتعديلها أو استبعادها، إضافة مفردات من

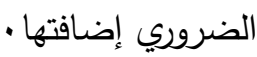

ب-الاتساق الاخلى للمفردات: 
مجلة دراسات فى مجال الإرشاد النفسي و التربوي ـ كلية التربية ـ جامعة أسيوط

قام الباحث بالتحقق من اتساق المقياس داخلياً، وذلك بحساب معاملات الارتباط بين

درجة كل مفردة والدرجة الكلية للمقياس، وذلك بعد تطبيق المقياس فى صورته الأولية (1) عبارة) على عينة الدراسة الاستطلاعية، كما هو موضح بجداول أرقام (1 ، r).

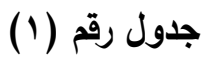

معاملات الارتباط بين درجة كل مفردة من مفردات البعد الأول ودرجة البعد ( ن= • م )

\begin{tabular}{|c|c|c|c|c|c|c|c|}
\hline معامل الارتباط & رقم & معامل الارتباط & رقم & معامل الارتباط & رقم & معامل الارتباط & رقم \\
\hline$* *, \neg \wedge \varepsilon$ & $\varepsilon$ & $* *, \neg 0 \wedge$ & r & $* *, 0 \wedge 7$ & r & $* *,, \vee \backslash 0$ & 1 \\
\hline$* * ., 079$ & $\wedge$ & $* *,, \vee \circ 9$ & v & $* *, \vee>10$ & 7 & $* *, \quad V \leq r$ & 0 \\
\hline$* *, 7 \vee 1$ & Ir & $* *,, \vee \diamond 0$ & 11 & זrד, •** & 1. & $* *$ *, ๆ & 9 \\
\hline$* *, T \vee r$ & 17 & $* * ., 009$ & 10 & $* *, \vee \wedge \wedge$ & $1 \varepsilon$ & $* *, \vee \backslash 9$ & r \\
\hline & & & & $* *, \vee r q$ & 11 & $* *, T r$. & iv \\
\hline
\end{tabular}

** دالة عند مستوى 1 . , .

ج-الصدق التمييزى:

قام الباحث باستخدام اختبار "مان ويتنى " Mann-Whitney U للأزواج المستقلة لمعرفة دلالة الفـروق بين الإبباعى الأعلى والإرباعى الأدنى على المقياس، كما يوضح ذلك

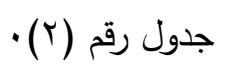

جدول رقم (r) (r) - (ب)

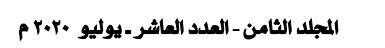
https://dapt.journals.ekb.eg 
د/مصطفى عبد المحسـن الحييى د/ إيمان صلاح الدين حسين الثريف أ/بيتر مجدى حبيب أبادير

دلالة الفروق بين الإرباعى الأعلى والإرباعى الأدنى

\begin{tabular}{|c|c|c|c|c|c|}
\hline مستوى الدلالة & $\begin{array}{l}\text { قيمة } \\
\text { " Z " }\end{array}$ & مجموع & رتب & ن & \\
\hline \multirow{2}{*}{ دال عند مستوى } & \multirow[b]{2}{*}{ T,EYT- } & $r \Lambda, .$. & $\varepsilon, \ldots$ & v & الإرباعى الأدنى \\
\hline & & Qr,,. & $11,0$. & $\wedge$ & الإرباعى الأعلى \\
\hline
\end{tabular}

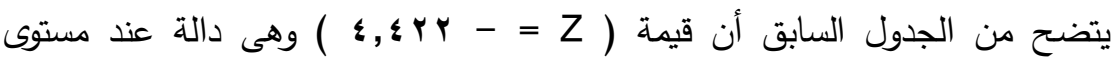

ا .,., مما يدل على وجود فروق بين درجات المرتفعين ودرجات المنخفضين على المقياس،

وهذا يؤكد قدرة المقياس على التمييز بين المرتفعين والمنخفضين مما يثير إلى صدق المقياس •

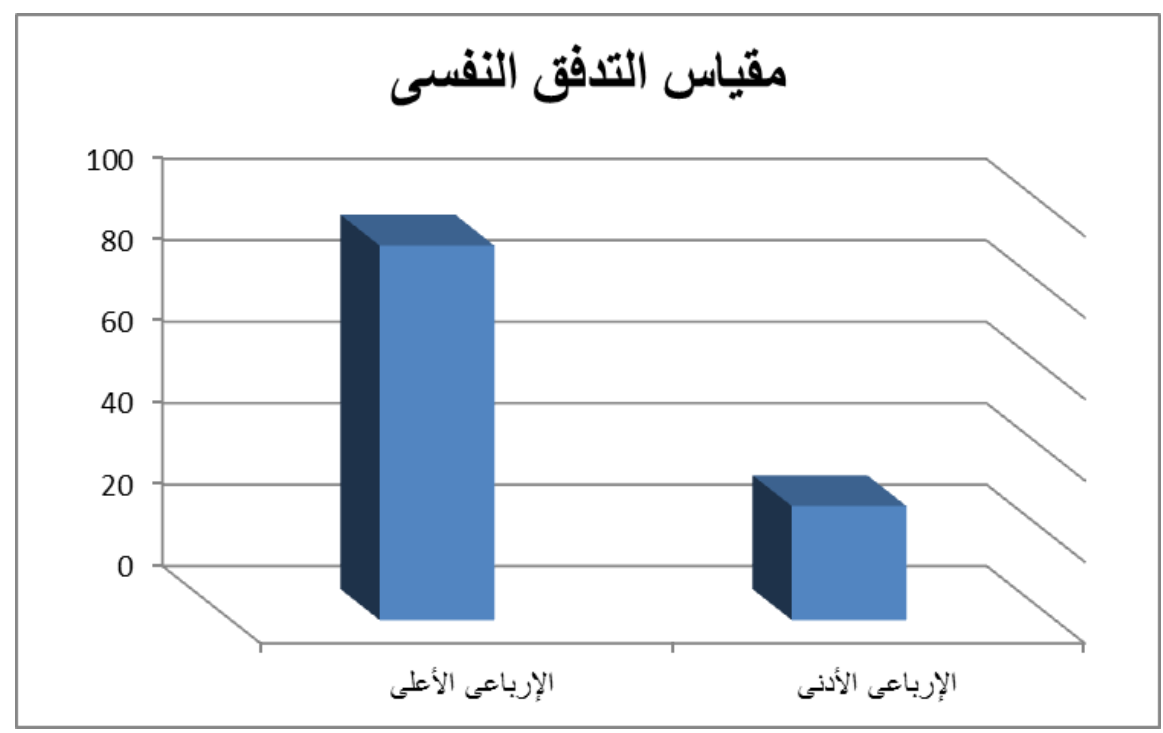

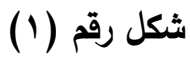

دلالة الفروق بين الإرباعى الأعلى والإرباعى الأدنى

ثانياً: الثبات:

اعتمد الباحث فى حساب الثبات على مايلى:

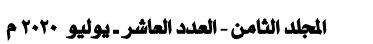

https://dapt.journals.ekb.eg 
مجلة دراسات فى مجال الإرشاد النفسي و التربوي ـ كلية التربية ـ جامعة أسيوط

\section{أ-طربقة إعادة الاختبار:}

قام الباحث بتطبيق المقياس على العينة الاستطلاعية، ثم أعاد تطبيقه على نفس

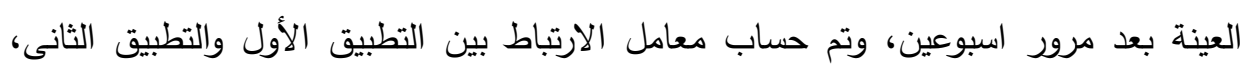

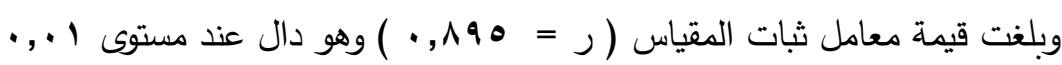

ب-طريقة معادلة ألفا كرونباك Alpha Cronbach Method استخدم الباحث معادلة ألفا كرونباك، وهى معادلة تستخدم فى إيضاح المنطق العام لثبات

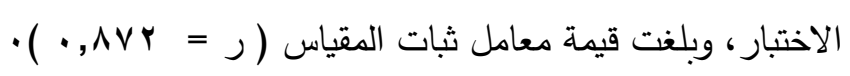

r-مقياس قلق الكلام للاطفال المعاقين عقلياً القابلين للتعلم: (أ) خطوات اعداد المقياس:

قام الباحث بإعداد مقياس قلق الكلام للأطفال المعاقين عقليًا القابلين للتعم المدمجين

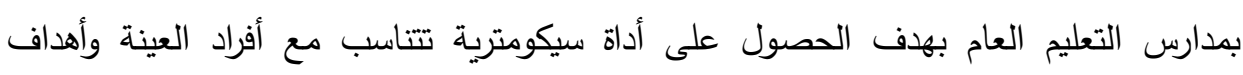
وطبيعة الدراسه لسببين ، أولهما: ان غالبية المقاييس المعدة للتطبيق قديمة نسبيًا ، وثانيهما: ان ان

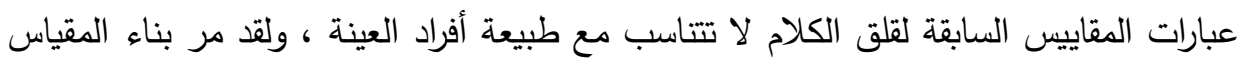

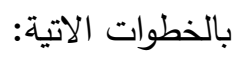

- الاطلاع على السمات المصاحبة لقلق الكلام لحمدى الفرماوى (T . . ب) واتخاذها مرجعًا نظريًا ستعتمد أبعادها فى قياس ظاهرة قلق الكلام.

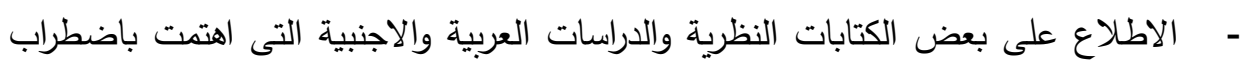
قلق الكلام. - الاطلاع على بعض المقاييس العربية والاجنبية المتعلقة بإضطراب قلق الكلام المستعملة

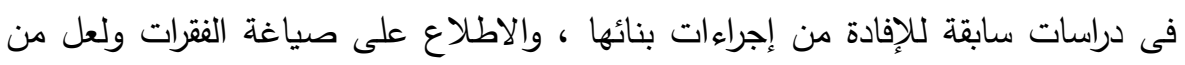
أبرز هذة المقاييس ما يلى: 1- مقياس الخوف الاجتماعى من التحدث أمام الاخرين إعداد منال مصطفى (ع ( ب ) 
د/مصطفى عبد المحسن الحديبى د/ إيمان صلاح الدين حسين الثريف ألبيتر مجدى حبيب أبادير

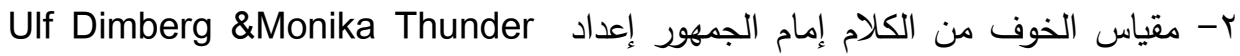
(2007)

Floey \& Spates (2001) مقياس قلق الكلام إعداد Scott (2001) كقياس قلق الكلام إعداد

فى ضوء المتغيرات المرتبطة بإضطراب قلق الكلام وطبيعة وخصائص أفراد العينة ، تم صياغة فقرات المقياس فى صورتها الأولية بما يناسب أسس العلاج الانتقائى والمتغيرات المرتبطة بإضطراب قلق الكلام؛ لتعبر عن اضطراب قلق الكلام للأطفال المعاقين عقليًا القابلين للتعلم المدمجين بمدارس التعليم العام ، حيث تمثل عدد عبارات مقياس قلق الكلام (qج) عبارة تقيس كل أبعاد اضطراب قلق الكلام الاربعة وقد روعى عند صياغة الفقرات ان تكون بصيغة المتكلم وان تقيس الفقرة فكرة واحدة فقط وعدم استعمال صيغة نفى النفى كى لا تربك المفحوص ولها بديلين هما: (نعم - لا) على ان تكون درجات كل فقرة على الترتيب (1 - · ) للعبارات الايجابية ، و ( • - (1) للعبارات السلبية.

(ب) الخصائص السيكومتربية لمقياس قلق الكلام: أولاً: الصدق: اعتمد الباحث فى حساب الصدق على ما يلى:

أ-الصدق المنطقى ( صدق المحكمين ):

تم عرض المقياس على مجموعة من المحكمين وذلك بهدف: التأكد من مناسبة مفرداته، تحديد غموض بعض المفردات لتعديلها أو استبعادها، إضافة مفردات من الضروري إضافتها . ب-الاتساق الاخلى للمفردات: 
مجلة در اسات فى مجال الإرشاد النفسي و التربوي ـ كلية التربية ـ جامعة أسيوط

قام الباحث بالتحقق من اتساق المقياس داخلياً، وذلك بحساب معاملات الارتباط بين

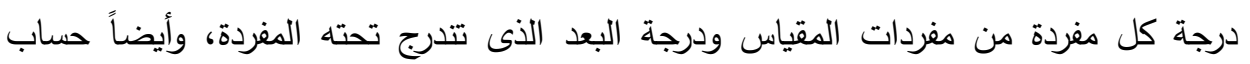

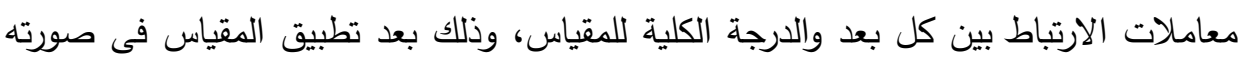

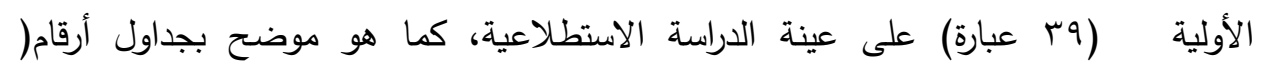
$\cdot\left(r_{6} \varepsilon_{6006} T_{6} V\right.$

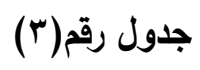

معاملات الارتباط بين درجة كل مفردة من مفردات البعد الأول ودرجة البعد ( ن= . ب )

\begin{tabular}{|c|c|c|c|c|c|c|c|}
\hline \multicolumn{8}{|c|}{ البعد الأول ( المظاهر البدنية ) } \\
\hline الارتباط معامل & رقم - - مق & معامل الارتباط & رقم & معامل الارتباط & رقم & معامل & رقم \\
\hline$* *,, \vee 01$ & $\varepsilon$ & $* *, \vee \backslash 9$ & r & $* *, 011$ & r & $* *, 79 r$ & 1 \\
\hline$* *$, T $\vee 0$ & $\wedge$ & $* *, \Lambda ו r$ & V & $* *, 79 r$ & 7 & $* *, \vee \vee \leqslant 0$ & 0 \\
\hline & & & & & & $* *, 7 \wedge 9$ & 9 \\
\hline
\end{tabular}

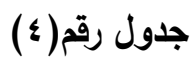

معاملات الارتباط بين درجة كل مفردة من مفردات البعد الثانى ودرجة البعد ( ن= . ب )

\begin{tabular}{|c|c|c|c|c|c|c|c|}
\hline \multicolumn{8}{|c|}{ البعد الثانى ( المظاهر المعرفية ) } \\
\hline معامل الارتباط ل & 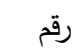 & 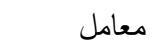 & 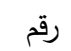 & 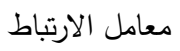 & 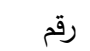 & معامل الارتباط & 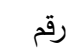 \\
\hline$* * \cdot, \wedge \leq r$ & Tr & **, & ir & $* *, \neg \wedge \wedge$ & 11 & $* *, \wedge T V$ & 1. \\
\hline$* * ., 09 r$ & iv & $* *,, \vee \wedge)$ & 17 & **, , Т & 10 & $* *, \wedge r$. & $1 \varepsilon$ \\
\hline & & & & $* *, 709$ & 19 & $* *, \vee \circ \vee$ & 11 \\
\hline
\end{tabular}


د/مصطفى عبد المحسن الحديبى د/ إيمان صلاح الدين حسين الثريف أ/بيتر مجدى حبيب أبادير

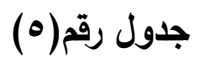

معاملات الارتباط بين درجة كل مفردة من مفردات البعد الثالث ودرجة البعد ( ن= • م )

\begin{tabular}{|c|c|c|c|c|c|c|c|}
\hline \multicolumn{8}{|c|}{ البعد الثالث ( المظاهر النفسية ) } \\
\hline معامل الارتباط & 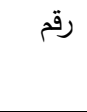 & معامل الارتباط & 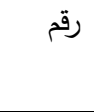 & معامل الارتباط & 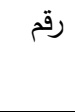 & معامل & 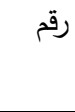 \\
\hline$* * ., 0 \wedge 9$ & r & $* *, \wedge \leq 1$ & r & $* *$, , s & r) & $* *, \wedge \wedge 1$ & $r$. \\
\hline$* *, T \vee \wedge$ & rV & $* *, 79 \leqslant$ & rt & $* *, 700$ & ro & $* *, \wedge r \varepsilon$ & $r \varepsilon$ \\
\hline$* *, . \vee 0$ & 㑑 & ***ת • & $r$. & $* *, \wedge \cdot \wedge$ & rq & $* *, 709$ & rᄉ \\
\hline
\end{tabular}

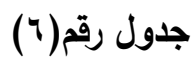

معاملات الارتباط بين درجة كل مفردة من مفردات البعد الرابع ودرجة البعد ( ن= • ب )

\begin{tabular}{|c|c|c|c|c|c|c|c|}
\hline \multicolumn{8}{|c|}{ البعد الرابع ( المظاهر اللغوية ) } \\
\hline الارتباط & رقم & معامل الارتباط & رقم & الارتباط & 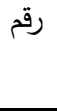 & معامل & رقم - - - مق \\
\hline$* *, \vee \vee 9 ०$ & ro & $* *, \Lambda I r$ & $r \leq$ & $* *, 7 \wedge 0$ & 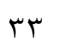 & $* *, \vee \curlyvee \wedge$ & r \\
\hline$* *, \vee \vee \vee \varepsilon$ & rq & $* *, \wedge \vee$. & r人 & $* *, \wedge \Gamma q$ & $r v$ & $* *, 710$ & דr \\
\hline
\end{tabular}

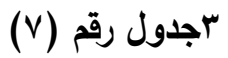

معاملات الارتباط بين درجة كل بعد والارجة الكلية للمقياس ( ن= • م )

\begin{tabular}{|c|c|c|c|}
\hline معامل الارتباط & البعد & معامل الارتباط & البعد \\
\hline$* * \cdot, \wedge \cdot \Sigma$ & المظاهر النفسية & $* *, \vee \vee 90$ & المظاهر البدنية \\
\hline **, YAT & المظاهر اللغوية & $* * \cdot, \wedge 10$ & المظاهر المعرفية \\
\hline
\end{tabular}

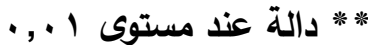

ج-الصدق التمييزى:

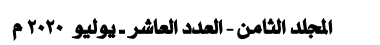

https://dapt.journals.ekb.eg 
مجلة در اسات فى مجال الإرشاد النفسي و التربوي ـ كلية التربية ـ جامعة أسيوط

قام الباحث باستخدام اختبار "مان ويتنى " Mann-Whitney U للأزواج المستقلة

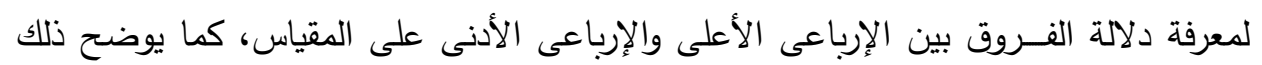
جدول رقم (^) - (^)

جدول رقم (^)

دلالة الفروق بين الإرباعى الأعلى والإرباعى الأدنى

\begin{tabular}{|c|c|c|c|c|c|}
\hline مستوى الدلالة & قيمة & الرجموع & رتب المتوسط & ن & \\
\hline \multirow{2}{*}{ دال عند مستوى } & \multirow[b]{2}{*}{ r, } & $r \wedge, \cdots$ & $\varepsilon, \ldots$ & V & الإرباعى الأدنى \\
\hline & & $q r, \ldots$ & $11,0$. & $\wedge$ & الإرباعى الأعلى \\
\hline
\end{tabular}

يتضح من الجدول السابق أن قيمة ( Z Z - I,r,r ) وهى دالة عند مستوى

I . , . مما يدل على وجود فروق بين درجات المرتغعين ودرجات المنخفضين على المقياس، وهذا يؤكد قدرة المقياس على التمييز بين المرتفعين والمنخفضين مما يشير إلى صدق المقياس •

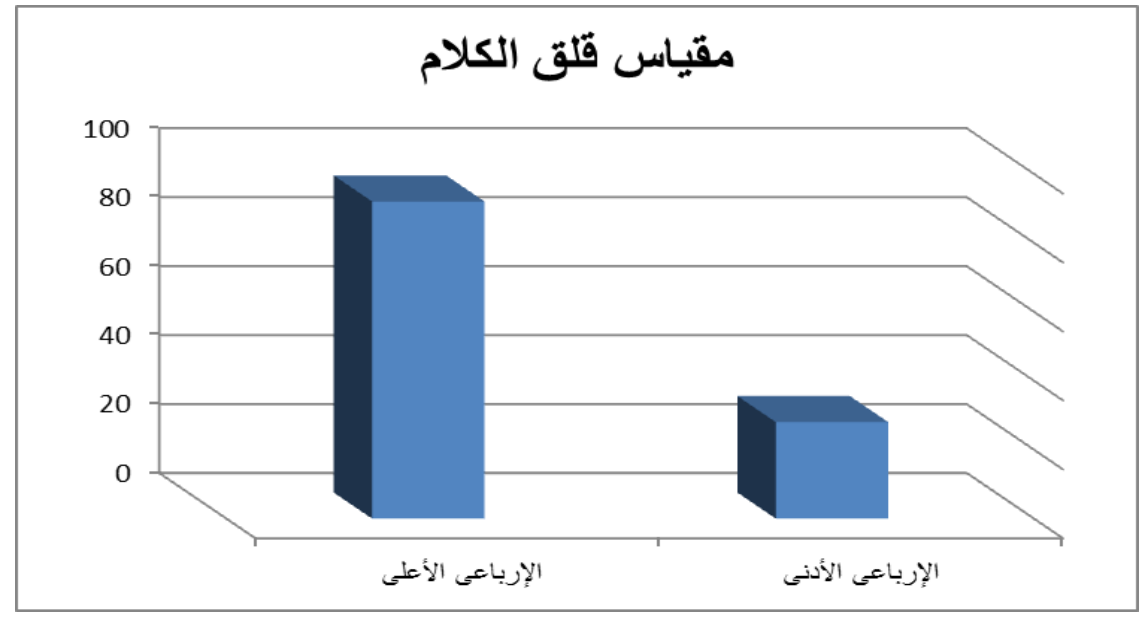

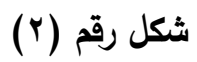

دلالة الفروق بين الإرباعى الأعلى والإرباعى الأدنى 
د/مصطفى عبد المحسن الحديبى د/ إيمان صلاح الدين حسين الثريف أ/بيتر مجدى حبيب أبادير

ثانياً: الثبات:

اعتمدت الباحثة فى حساب الثبات على مايلى:

أ- طريقة إعادة الاختبار:

قام الباحث بتطبيق المقياس على العينة الاستطلاعية، ثم أعاد تطبيقه على نفس

العينة بعد مرور اسبوعين، وتم حساب معامل الارتباط بين التطبيق الأول والتطبيق الثانى كما

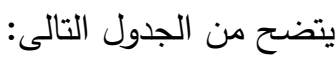

جدول (9)

معاملات ثبات المقياس وأبعاده بطريقة إعادة الاختبار

\begin{tabular}{|c|c|}
\hline معامل الثبات & المقياس وأبعاده \\
\hline$* * \cdot, \Delta r r$ & المظاهر البدنية \\
\hline$* * \cdot, A Y Y$ & المظاهر المعرفية \\
\hline$* * \cdot, \wedge 9 \sum$ & المظاهر النفسية \\
\hline$* *$, , 04 & المظاهر اللغوية \\
\hline$* * \cdot, \wedge \wedge 1$ & مقياس قلق الكلام \\
\hline
\end{tabular}

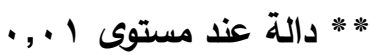

ب-طريقة معادلة ألفا كرونباك Alpha Cronbach Method :

استخدم الباحث معادلة ألفا كرونباك، وهى معادلة تستخدم فى إيضاح المنطق العام لثبات الاختبار ، وجدول (• (1) يوضح معاملات ثبات المقياس وأبعاده .

جدول (1.) - (1) - (2) 
مجلة دراسات فى مجال الإرشاد النفسي و التربوي ـ كلية التربية ـ جامعة أسيوط

معاملات ثبات المقياس وأبعاده بطريقة ألفا كرونباك

\begin{tabular}{|c|c|}
\hline معامل الثبات & الدقياس وأبعاده \\
\hline$\cdot, A \cdot 0$ & المظاهر البدنية \\
\hline$\cdot, \wedge \leqslant \vee$ & المظاهر المعرفية \\
\hline אזי人, & المظاهر النفسية \\
\hline ת ש ה ג, & المظاهر اللغوية \\
\hline$\therefore, 10$ & مقياس قلق الكلام \\
\hline
\end{tabular}

عاشرًا: نتائج الدراسة:

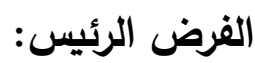

الذى ينص على:" توجد علاقة ارتباطية دالة احصائية بين التدفق النفسى وقلق

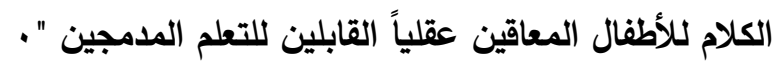

للتحقق من صحة هذا الفرض قام الباحث بحساب معامل الارتباط بين كل من درجات

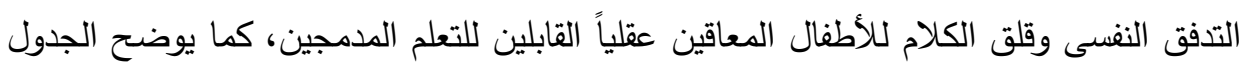

التالى قيم معاملات الارتباط

جدول رقم (1) - (1)

المتوسطات والانحرافات المعيارية لدرجات مقياس قلق الكلام وأبعاده

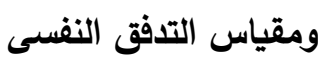

\begin{tabular}{|c|c|c|}
\hline الانحراف المعيارى & المتوسط & \\
\hline $1,1 \cdot v$ & 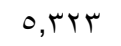 & المظاهر البدنية \\
\hline$\cdot, 994$ & $\vee, O \wedge 1$ & المظاهر المعرفية \\
\hline $1, \Lambda \cdot V$ & $V, V \leq r$ & المظاهر النفسية \\
\hline$\cdot 940$ & $0,0 \leqslant 1$ & المظاهر اللغوية \\
\hline$r, \Sigma \wedge r$ & $r 7,19 \leq$ & مقياس قلق الكلام \\
\hline 1, ह & $r, 19 r$ & مقياس التدفق النفسى \\
\hline
\end{tabular}

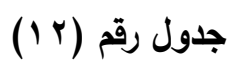

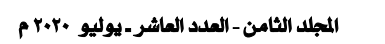

https://dapt.journals.ekb.eg 
د/مصطفى عبد المحسن الحديبى د/ إيمان صلاح الدين حسين الثريف ألبيتر مجدى حبيب أبادير معاملات الارتباط بين التدفق النفسى وقلق الكلام للأطفال المعاقين عقلياً القابلين للتعلم

$$
\text { المدمجين ( ن = اب ) }
$$

\begin{tabular}{|c|c|c|c|c|c|}
\hline \multicolumn{5}{|c|}{ مقياس قلق الكلام وأبعاده } & \multirow{3}{*}{ العبارات } \\
\hline قلق & المظاهر & المظاهر & المظاهر & المظاهر البدنية & \\
\hline الكلام & اللغوية & النفسية & المعرفية & & \\
\hline$* *,, \vee \vee \wedge-$ & $* *, V \backslash Y-$ & $* *,, V \leq r-$ & $* *,, \vee 0 .-$ & $* *,$, Y Y O- & التدفق النفسى \\
\hline
\end{tabular}

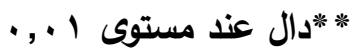


مجلة در اسات فى مجال الإرشاد النفسي و التربوي ـ كلية التربية ـ جامعة أسيوط

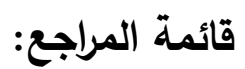

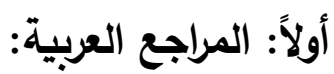

1- إبراهيم محمود أبو الهدى (1) • (1) . دراسة سيكومترية كلينيكية لقلق المستقبل وعلاقتة بمعنى الحياة ووجهة الضبط لدى عينة من المعاقين بصرياً والمبصرين.

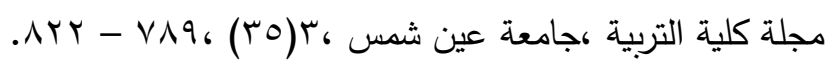

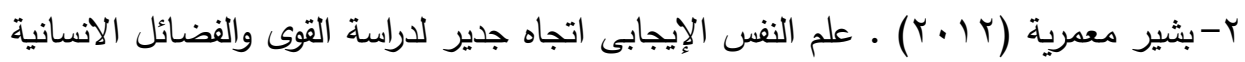
، دراسات نفسية، العدد ب .

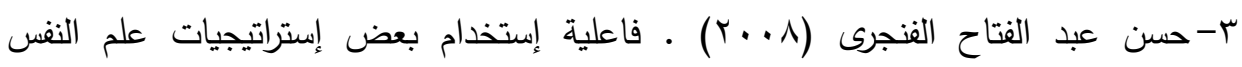
الايجابى فى التخفيف من قلق المستقبل ـ المجلة المصرية للدراسات

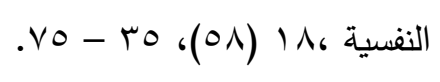

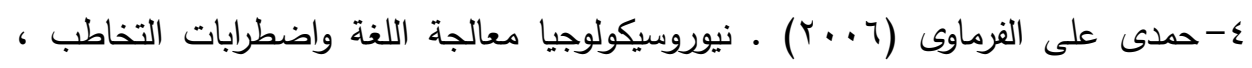

$$
\text { القاهرة : مكتبة الأنجلو المصرية. }
$$

ه- خالد بن عايد الحبوب وأمينة بنت حمد الرويلي (1) (1) ـ منهج التدريبات السلوكية والمعرفية للطلبة القابلين للتدريب من ذوي الإعاقة العقلية، الطبعة

العربية، دار اليازوري العلمية للنشر والتوزيع، عمان، الأردن.

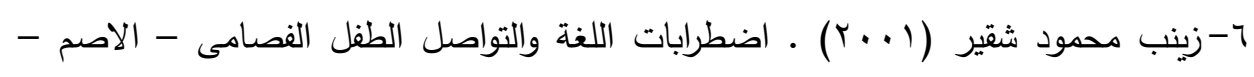

الكفيف - التخلف العقلى - صعوبات التعلم ، القاهرة ، دار النهضة.

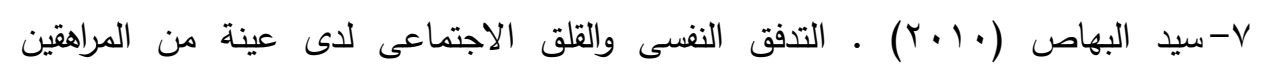

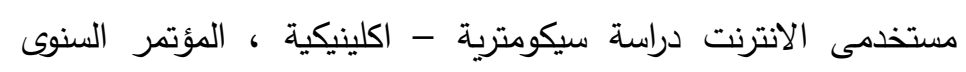

الخامس ، جامعة عين شمس؛ مركز الارشاد النفسى - مصر. 
د/مصطفى عبد المحسن الحديبى د/ إيمان صلاح الدين حسين الشريف أ/بيتر مجدى حبيب أبادير

1- صديق ومحمد السيد (q . . r) . التدفق النفسى وعلاقتة ببعض العوامل النفسية لدى طلاب الجامعة ، مجلة دراسات نفضية - المجلد - r العدد 9 - - مصر.

9- عبد العزيز السيد الثخص (99VV) ( I9 ) اضطرابات النطق والكلام ، الرياض ، المملكة العربية السعودية ، شركة الصفات الذهنية المحدودة.

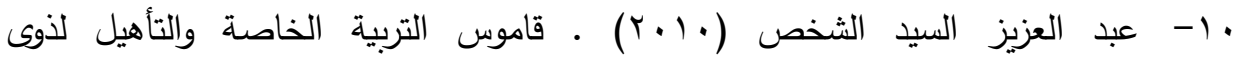
الاحتياجات الخاصة انجليزى - عربى ، طء ،القاهرة : مكتبة الانجلو

$$
\text { المصريبة. }
$$

ا ا- عبد العزيز حيدر وأنس اسود (T ( ب ) • التدفق النفسى على وفق التفكير الايجابى لدى طلبة الجامعة، مجلة كلية التربية للبنات للعلوم الانسانية العدد (1) -

$$
\text { جامعة الكوفة ، العراق. }
$$

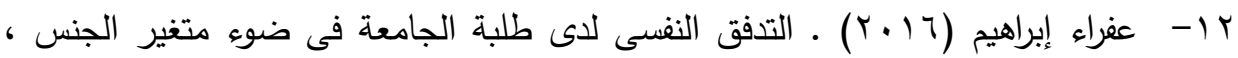
والتخصص الدراسى، مجلة الاستاذ ، العدد الخاص بالمؤتمر العلىى

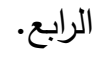

با- ـ ليلى أحمد كرم الدين (990) (190) برنامج التتمية العقلية واللغوية للأطفال المعاقين عقلياً القابلين للتعليم من أطفال مدارس التربية الفكرية ، وزارة التربية والتعليم ، المؤتمر القومى الاول للتربية الخاصة ، القاهرة.

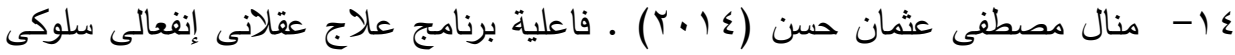
فى خفض درجة الخوف من التحدث أمام الاخرين لاى عينة من طلاب الجامعة "دراسة إكلينيكية". 
مجلة در اسات فى مجال الإرشاد النفسي و التربوي ـ كلية التربية ـ جامعة أسيوط ثانياً: المراجع الاجنبية:

15- Asl. S.T.S .Sadeghi. K..Bakhtiari, M..Khazaie, H..Rezaei, M..Ahmadi, S.M. (2014). The Effectiveness of Group Postive Psychotherapy on Improving the Depression and Increasing the Happiness of the Infertile Women: clinical Trial. European journal of Experimental Biology.

16- Bonnie Camp (2007) . Verbal mediation in young Aggressive boys, Journal of abnormal psychology, vo186, issue2, 145-153.

17- Cheek, J, M.,\& Buss,A. H. (1981) . Shyness and sociability. Journal of Personality and Social Psychology.

18- Csikszentmihaly Mihalyi (2008) . Flow The Psychology of Optimal Experience. Paperback - July 2008.

19- Floey, T., \& Spates, R. (2001). Eye Movement Desensitization of Public Speaking Anxiety: Apartial Dismantling. Journal of Behav. Ther. \& Exp. Psychiat, 26, (4), $321-329$. 
د/مصطفى عبد المحسن الحديبى د/ إيمان صلاح الدين حسين الثريف ألبيتر مجدى حبيب أبادير

20- Jackson, S.A. , \& Marsh, H.W. (1996) . Development and validation of a scale to measure optimal experience: The Flow State Scale. Journal of Sport and Exercise Psychology, 68(2), 109-121.

21- Joseph A.Goldfarb (2009).Effects of acceptance versus Cognitive restructuring on public speaking anxiety in college Students, Hofstra University: department of Philosophy.

22- McCroskey J. C. (1977). Oral communication apprehension: A summary of recent theory, publication, reprinted with Permission of the publisher, Inc.

23- Meyer, P. S. Johnson, D. P. Parks, A. C. Iwanski, C. \& Penn, D. L. (2012). Positive living: A pilot study of group positive psychotherapy for people with schizophrenia. Journal of Positive Psychology.

24- Michael F. Detweiler (2005). Para verbal avoidance during Public speaking: the relationship between selfdisclosure And social anxiety, West Virginia university: college of Arts, Department of psychology. 
مجلة در اسات فى مجال الإرشاد النفسي و التربوي ـ كلية التربية ـ جامعة أسيوط

25- Moneta, G. B., \& Csikszentmihalyi, M. (1996). The effect of perceived challenges and skills on the quality of subjective experience. Journal of Personality, 64, 275310.

26- Scott, R. (2001). The Use of Eye Movement Desensitization and Reprocessing in Treating Public Speaking Anxiety/Phobia for Individuals of High, Moderate, and Low Absorption. Ph. D. Dissertation, Saybrook Institute, San Francisco, California.

27- Seligman, M. E. P. (2002). Authentic happiness: Using the new positive psychology to realize your potential for lasting fulfillment. New York: Free Press.

28- Ulf D., and Monika T. (2007). Speech anxiety and rapid Emotional reaction to angry and happy facial expression, Journal of psychology. 